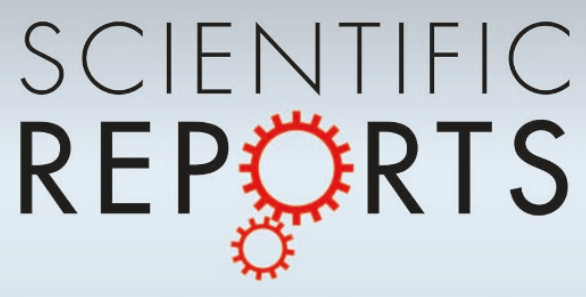

OPEN

SUBJECT AREAS:

MECHANICAL

ENGINEERING

SYNTHESIS AND PROCESSING

Received

7 November 2013

Accepted

4 February 2014

Published

5 March 2014

Correspondence and requests for materials should be addressed to

K.R. (konradr@asu. edu) or K.K.V.

(varanasi@mit.edu) $*$ These authors
contributed equally to
this work.

\title{
Dropwise Condensation of Low Surface Tension Fluids on Omniphobic Surfaces
}

\author{
Konrad Rykaczewski ${ }^{*}$, Adam T. Paxson 2*, Matthew Staymates ${ }^{3}$, Marlon L. Walker ${ }^{3}$, Xiaoda Sun', \\ Sushant Anand ${ }^{2}$, Siddarth Srinivasan ${ }^{4}$, Gareth H. McKinley ${ }^{2}$, Jeff Chinn ${ }^{5}$, John Henry J. Scott ${ }^{3}$ \\ \& Kripa K. Varanasi ${ }^{2}$
}

\begin{abstract}
${ }^{1}$ School for Engineering of Matter, Transport and Energy, Arizona State University, Tempe, AZ, ${ }^{2}$ Department of Mechanical Engineering, Massachusetts Institute of Technology, Cambridge, MA, ${ }^{3}$ Material Measurement Laboratory, National Institute of Standards and Technology, Gaithersburg, MD, ${ }^{4}$ Department of Chemical Engineering, Massachusetts Institute of Technology, Cambridge, MA, ${ }^{5}$ Integrated Surface Technologies Inc., Menlo Park, CA.
\end{abstract}

Compared to the significant body of work devoted to surface engineering for promoting dropwise condensation heat transfer of steam, much less attention has been dedicated to fluids with lower interfacial tension. A vast array of low-surface tension fluids such as hydrocarbons, cryogens, and fluorinated refrigerants are used in a number of industrial applications, and the development of passive means for increasing their condensation heat transfer coefficients has potential for significant efficiency enhancements. Here we investigate condensation behavior of a variety of liquids with surface tensions in the range of 12 to $28 \mathrm{mN} / \mathrm{m}$ on three types of omniphobic surfaces: smooth oleophobic, re-entrant superomniphobic, and lubricant-impregnated surfaces. We demonstrate that although smooth oleophobic and lubricant-impregnated surfaces can promote dropwise condensation of the majority of these fluids, re-entrant omniphobic surfaces became flooded and reverted to filmwise condensation. We also demonstrate that on the lubricant-impregnated surfaces, the choice of lubricant and underlying surface texture play a crucial role in stabilizing the lubricant and reducing pinning of the condensate. With properly engineered surfaces to promote dropwise condensation of low-surface tension fluids, we demonstrate a four to eight-fold improvement in the heat transfer coefficient.

\footnotetext{
C ondensation of vapor is a crucial part of a wide range of industrial processes from power generation and distillation to liquefaction and refrigeration ${ }^{1-6}$. In the past eight decades, significant attention has been devoted to the study of underlying mechanisms, methods, and materials for enhancing the condensation heat transfer rate of steam by promoting dropwise condensation. In particular, hydrophobic coatings on intrinsically hydrophilic metal condenser surfaces have been used to increase condensation heat transfer coefficients of water by up to an order of magnitude by forcing steam to condense into individual drops instead of a thick thermally-insulating film ${ }^{7-12}$. More recent studies have utilized nanoengineered textured surfaces to further enhance dropwise condensation ${ }^{13-21}$.

In contrast, fewer studies have been devoted to finding methods of enhancing condensation of lower surface tension liquids. Some strategies have been pursued for enhancement of filmwise condensation heat transfer of methane, refrigerants, and other low-surface tension fluids, including passive techniques such as fabrication of fins and channels on the condenser surface ${ }^{4,22-25}$ and active methods such as vibration, electrostatic fields, and suction $^{25,26}$. However, these techniques remain limited by the fundamental constraint of filmwise wetting behavior and could greatly benefit from promoting dropwise condensation. Previous studies on dropwise condensation are primarily devoted to steam, with a few studies of fluids with high or moderate surface tension ${ }^{27-31}$ or $^{2}$ Marangoni dropwise condensation of binary mixtures ${ }^{32-38}$. To our knowledge, dropwise condensation of fluids with a surface tension, $\gamma_{l v}$, less than $20 \mathrm{mN} / \mathrm{m}$ has not yet been demonstrated, since many of the materials commonly used as non-wetting modifiers do not have a critical solid surface energy low enough to prevent filmwise wetting. For example, methane $\left(\gamma_{l v}=9 \mathrm{mN} / \mathrm{m}\right.$ at $\left.293 \mathrm{~K}\right)$ and the refrigerant R-134a $\left(\gamma_{l v}=18 \mathrm{mN} / \mathrm{m}\right.$ at $90 \mathrm{~K}$ ) will both spread on a poly-tetrafluoroethylene surface (PTFE, $\gamma_{c}=18 \mathrm{~mJ} / \mathrm{m}^{2}$ ) and would exhibit filmwise condensation $^{6,39}$. Accordingly, promotion of dropwise condensation necessitates the use of highly-fluorinated low-surface energy materials such as trichloro $\left(1 \mathrm{H}, 1 \mathrm{H}, 2 \mathrm{H}, 2 \mathrm{H}\right.$-perfluorooctyl) silane (fluorosilane, $\gamma_{c}=10.1 \mathrm{~mJ} /$ $\mathrm{m}^{2}$, see Supporting Materials). However, even on these surfaces, the drop contact angle will be significantly below $90^{\circ}$.
} 

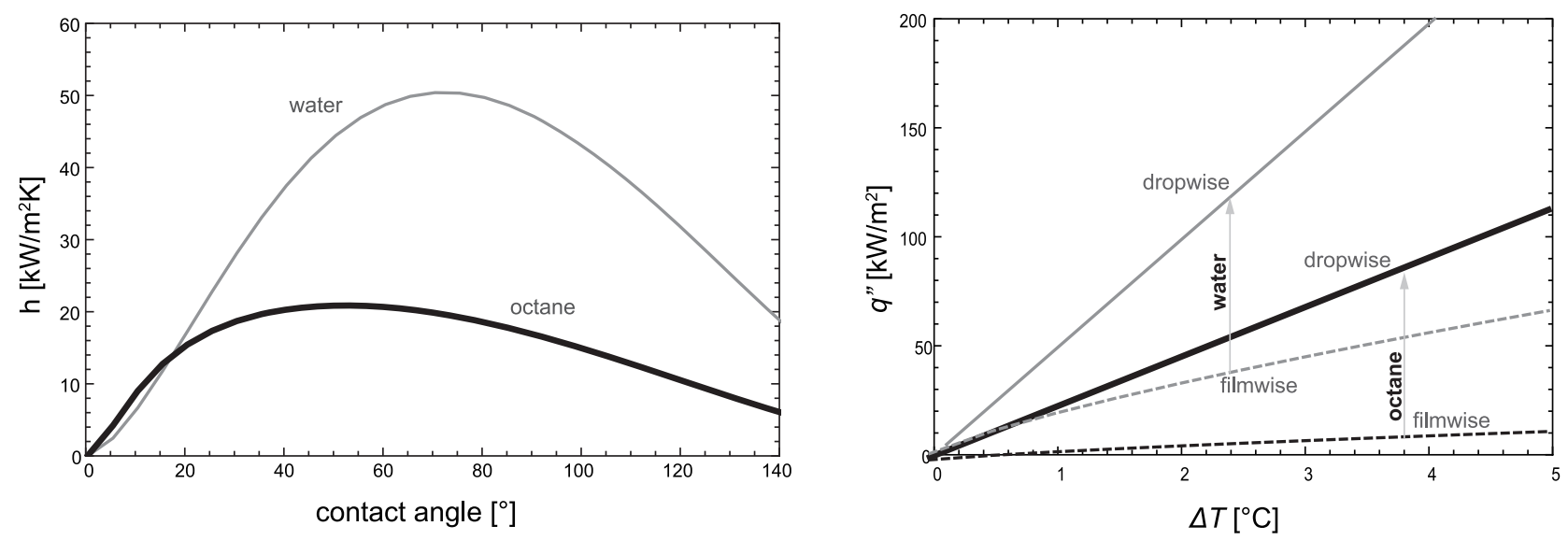

Figure 1 Estimated heat transfer coefficient for low-surface tension fluids. (a) Heat transfer coefficient estimated by Kim and Kim model ${ }^{42}$ for water and octane with fixed base diameters at $1.4 \mathrm{~mm}$ for octane and $2 \mathrm{~mm}$ for water. (b) Estimated increase in heat flux $\left(q^{\prime \prime}\right)$ vs. subcooling $(\Delta T)$ for filmwise and dropwise condensation of octane and water.

Since increases in drop contact angle above $90^{\circ}$ have been shown to significantly affect the heat transfer coefficient, $h^{16,40,41}$, a decrease of contact angle is also likely to impact $h$. To quantify this effect, we used a model developed by Kim and $\mathrm{Kim}^{42}$ to explore heat transfer during condensation of drops with contact angles less than $90^{\circ}$. We estimated the variation of the heat transfer coefficient with contact angle for an illustrative low-surface tension fluid, octane, at a saturation temperature of $293 \mathrm{~K}$ condensing on a subcooled vertical surface with contact angle varying between $0^{\circ}$ and $150^{\circ}$ (see Supporting Information for details of the analysis). The plot in Fig. 1 shows that the heat transfer coefficient decreases as the contact angle decreases below about $90^{\circ}$ for water, and below about $60^{\circ}$ for octane. Despite this effect, a comparison of $h$ during filmwise and dropwise condensation of water and octane, shown in Figure $1 \mathrm{~b}$ as the slope of $q^{\prime \prime}$ vs. $\Delta T$, reveals about seven-fold increase in heat transfer coefficients from about $3 \mathrm{~kW} / \mathrm{m}^{2} \mathrm{~K}$ to about $20 \mathrm{~kW} / \mathrm{m}^{2} \mathrm{~K}$ in the case of octane.

Motivated by the above results, we examine the fundamental design criteria of a surface for promoting dropwise condensation of low-surface tension fluids. The most basic condenser surface must have a critical surface energy appreciably lower than that of the condensate to result in a finite wetting angle, and a contact angle hysteresis low enough to allow condensate drops to shed before they coalesce to form a continuous film ${ }^{29,43}$. Beyond a simple smooth nonwetting surface, textured superhydrophobic surfaces have been employed to further enhance the dropwise condensation heat transfer coefficient. If the surface is sufficiently rough, it will promote a mode of water condensation commonly referred to as "jumping condensation" $13,44-47$. However, this phenomenon relies on a large difference in surface energy between the condensate and solid surface in order to promote a robust Cassie-Baxter state ${ }^{48-50}$. In the case of low-surface tension liquids, a Cassie-Baxter state is significantly more challenging to maintain. Superomniphobic surfaces have been demonstrated to overcome this challenge by employing re-entrant textures to promote a Cassie-Baxter state even with low-surface tension liquids such as ethanol $\left(\gamma_{l v}=24.8 \mathrm{mN} / \mathrm{m}\right)^{51-53}$. However, as with water condensate flooding of superhydrophobic surfaces, it is possible that re-entrant surfaces might lose their superomniphobic characteristics during condensation of low-surface tension fluids due to nucleation and growth of condensate drops within the texture $\mathrm{e}^{54-58,14}$. To overcome the challenge of condensate impalement, Anand et al. ${ }^{17}$ recently demonstrated that the departure diameter of condensing water drops can also be significantly decreased by impregnating a micro/nano-textured surface with a thin film of a lubricant that is immiscible with water. Such lubricant-impregnated surfaces have been shown to possess omniphobic, low hysteresis, self-cleaning, self-healing properties ${ }^{59-66}$
Here, we investigate the condensation of a variety of liquids with low surface tensions (12 to $28 \mathrm{mN} / \mathrm{m}$ ) on smooth oleophobic, lubricant-impregnated, and textured superomniphobic surfaces. Specifically, we used a custom built condensing chamber to study condensation of perfluorohexane, pentane, hexane, octane, isopropanol, ethanol, toluene, and, as a reference, water. The surfaces tested in the present study include both smooth and textured silicon wafers functionalized with fluorosilane coatings. The textured samples were vapor-deposited alumina-silica nanotextures ${ }^{67}$ (Fig. 2a), spray-coated re-entrant structures ${ }^{68}$ (Fig. 2b), and microposts (Fig. 2c). Wettability and condensation of all the textured surfaces was studied before and after imbibition with Krytox perfluorinated oil (Krytox-1506 from DuPont, Fig. 2d, e, f). This lubricant was selected primarily because its surface tension $\left(\gamma_{l v}=17 \mathrm{mN} / \mathrm{m}\right)$ is low enough to promote dropwise condensation of most condensed fluids while avoiding cloaking $^{17,64}$, and also because of its low vapor pressure, broad chemical inertness, and immiscibility with most of the condensed fluids.

\section{Results}

Wettability and contact angle hysteresis. Advancing and receding contact angles and hysteresis of the condensing liquids on the smooth oleophobic, nanotextured, and Krytox-impregnated nanotextured surfaces were measured using the pendant drop method. On the nanotexture, although the advancing contact angle of water was greater than $160^{\circ}$ with a contact angle hysteresis less than $5^{\circ}$, we found that all low-surface tension liquids spread over the texture. On the superomniphobic surface, ethanol wet in a Cassie-Baxter state with an advancing angle of $147 \pm 3^{\circ 68}$, and the $n$-alkanes wet in the Wenzel state with an advancing contact angle of $\sim 50^{\circ}$. Since the surface is 50\% PMMA, it was incompatible with toluene and isopropanol. Perfluorohexane spread completely on all surfaces due to its low surface tension, and since it is almost completely miscible with Krytox, it also spread on all lubricant-impregnated surfaces. The contact angles of the non-spreading liquids on the smooth oleophobic surface and Krytox-imbibed nanotexture are shown in Table 1.

Condensation behavior on smooth and textured surfaces. Next, we investigated condensation behavior of all fluids on four surfaces: smooth oleophobic wafer, dry superomniphobic texture, and the Krytox-impregnated and unimpregnated nanotexture. On the flat oleophobic surface, we observed continual formation and shedding of drops of all fluids with exception of perfluorohexane (Fig. 3a also see Supplemental Video 1 for example of pentane condensation on the flat oleophobic surface). For the fluids with which the superomniphobic texture was compatible, namely water, ethanol, and 
a

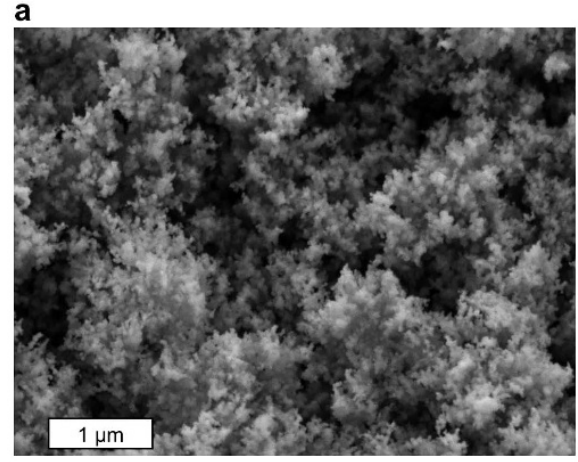

d

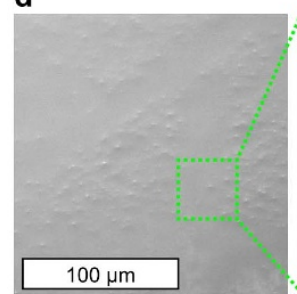

b

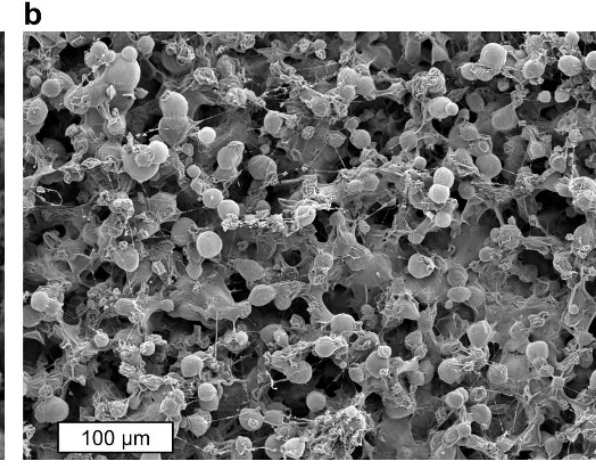

e

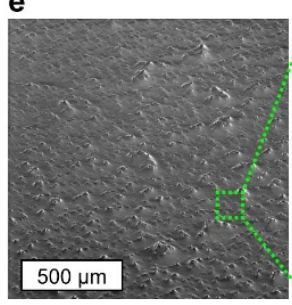

c

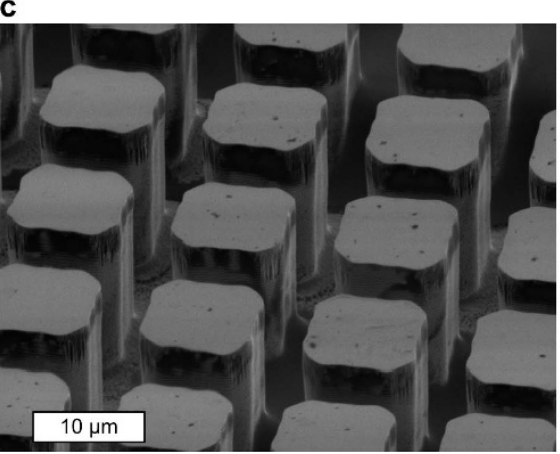

f
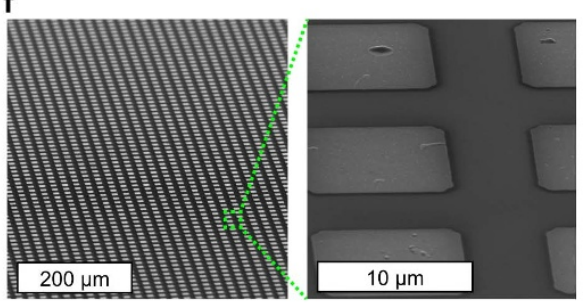

Figure $2 \mid$ Textured surfaces before and after lubricant impregnation. (a) vapor-deposited alumina-silica nanotexture. (b) re-entrant superomniphobic texture. (c) Silicon microposts etched via photolithography. (d) Krytox-impregnated nanotexture. (e) Krytox-impregnated superomniphobic texture. (f) Krytox-impregnated microposts.

the $n$-alkanes, the surface exhibited filmwise condensation. On the unimpregnated nanotexture, although condensation of water led to self-propelled jumping droplet motion, all of the low-surface tension fluids flooded the surface (Fig. 3b). Finally, on the Krytox-impregnated nanotexture, condensation of water, toluene, pentane, octane, and hexane led to continual formation and shedding of drops (Fig. 3c) whereas condensation of perfluorohexane, ethanol, and isopropanol, led to filmwise condensation.

The continual shedding of drops of all liquids (with exception of perfluorohexane) from the smooth oleophobic surface can be explained by its combination of moderately high contact angle and low contact angle hysteresis ${ }^{39}$. However, since the advancing contact angles of all of low-surface tension fluids on the silanized solid was significantly below $90^{\circ}$ (see Table 1 ), the addition of surface roughness should amplify the wetting properties of the surface according to Wenzel's equation ${ }^{69,70}$ :

$$
\cos \left(\theta_{w}\right)=r \cos \left(\theta_{e}\right)
$$

where $\theta_{w}$ and $\theta_{e}$ are the Wenzel and Young equilibrium contact angles, respectively, and $r$ is the ratio of the actual and projected areas. Hence, flooding of a textured silanized surface would be expected whenever condensing a low-surface tension fluid with an equilibrium contact angle less than $90^{\circ}$. However, such wettability arguments cannot be used to explain condensation behavior on the re-entrant superomniphobic surfaces. These surfaces have been shown to repel macroscale drops of ethanol and other low surface tension liquids due to their re-entrant geometrical features, where the wetting state is described by a modified Cassie-Baxter equation ${ }^{52,68}$. During condensation, since nuclei of condensing liquids have critical diameters of only a few nanometers ${ }^{25}$, they can easily nucleate within the roughness features of the re-entrant texture, similar to what was shown previously for water ${ }^{54-57,14,58}$. This behavior prevents formation of the Cassie-Baxter wetting state necessary for omniphobicity ${ }^{51}$ and leads to the flooding observed on the spray-coated superomniphobic surface during condensation.

Condensation behavior on lubricant-impregnated surfaces. Impregnation of the textured surfaces with the perfluorinated oil dramatically alters macroscale wetting and condensation behavior of all the fluids and highlights the importance of the surface morphology. The wetting states for all of the condensing liquids on the Krytox-impregnated nanotexture, except for perfluorohexane

Table 1 | Surface tension, $\sigma_{l v}$, advancing contact angle, $\theta_{a}$, receding contact angle, $\theta_{r}$, and contact angle hysteresis, $\Delta \theta$, of nonspreading condensing liquids measured on smooth oleophobic surface and Krytox-impregnated nanotexture

\begin{tabular}{|c|c|c|c|c|c|c|c|}
\hline \multirow[b]{2}{*}{ liquid } & \multirow[b]{2}{*}{$\begin{array}{c}\sigma_{l v}\left(25^{\circ} \mathrm{C}\right) \\
{[\mathrm{mN} / \mathrm{m}]}\end{array}$} & \multicolumn{3}{|c|}{$\begin{array}{l}\text { smooth oleophobic surface } \\
\qquad\left(\gamma_{c}=10.1 \mathrm{mN} / \mathrm{m}\right)\end{array}$} & \multicolumn{3}{|c|}{$\begin{array}{l}\text { Krytox-impregnated nanotexture } \\
\qquad(\gamma / v=17 \mathrm{mN} / \mathrm{m})\end{array}$} \\
\hline & & $\begin{array}{c}\theta_{a} \\
{[\mathrm{deg}]}\end{array}$ & $\begin{array}{c}\theta_{r} \\
{[\mathrm{deg}]}\end{array}$ & $\begin{array}{c}\Delta \theta \\
{[\mathrm{deg}]}\end{array}$ & $\begin{array}{c}\theta_{a} \\
{[\mathrm{deg}]}\end{array}$ & $\begin{array}{c}\theta_{r} \\
{[\mathrm{deg}]}\end{array}$ & $\begin{array}{c}\Delta \theta \\
{[\mathrm{deg}]}\end{array}$ \\
\hline water & 72.7 & $119.5 \pm 2.1$ & $92.3 \pm 2.7$ & $27.2 \pm 3.5$ & $118.8 \pm 1.0$ & $116.8 \pm 0.5$ & $2.0 \pm 0.8$ \\
\hline toluene & 27.9 & $75.3 \pm 1.2$ & $45.0 \pm 1.7$ & $30.3 \pm 1.5$ & $66.0 \pm 1.0$ & $35.3 \pm 2.5$ & $30.7 \pm 3.1$ \\
\hline pentane & 15.1 & $50.3 \pm 0.5$ & $9.3 \pm 1.7$ & $41.0 \pm 2.2$ & $35.3 \pm 0.5$ & $5.2 \pm 2.1$ & $20.1 \pm 1.5$ \\
\hline hexane & 18.0 & $57.3 \pm 2.5$ & $30.7 \pm 1.2$ & $26.7 \pm 1.5$ & $44.0 \pm 1.0$ & $11.3 \pm 3.5$ & $32.7 \pm 4.0$ \\
\hline octane & 21.1 & $66.7 \pm 0.6$ & $34.7 \pm 0.6$ & $24.0 \pm 1.0$ & $55.3 \pm 0.6$ & $43.0 \pm 3.6$ & $12.3 \pm 3.8$ \\
\hline perfluoro-hexane & 12.0 & 0.0 & 0.0 & 0.0 & 0.0 & 0.0 & 0.0 \\
\hline
\end{tabular}



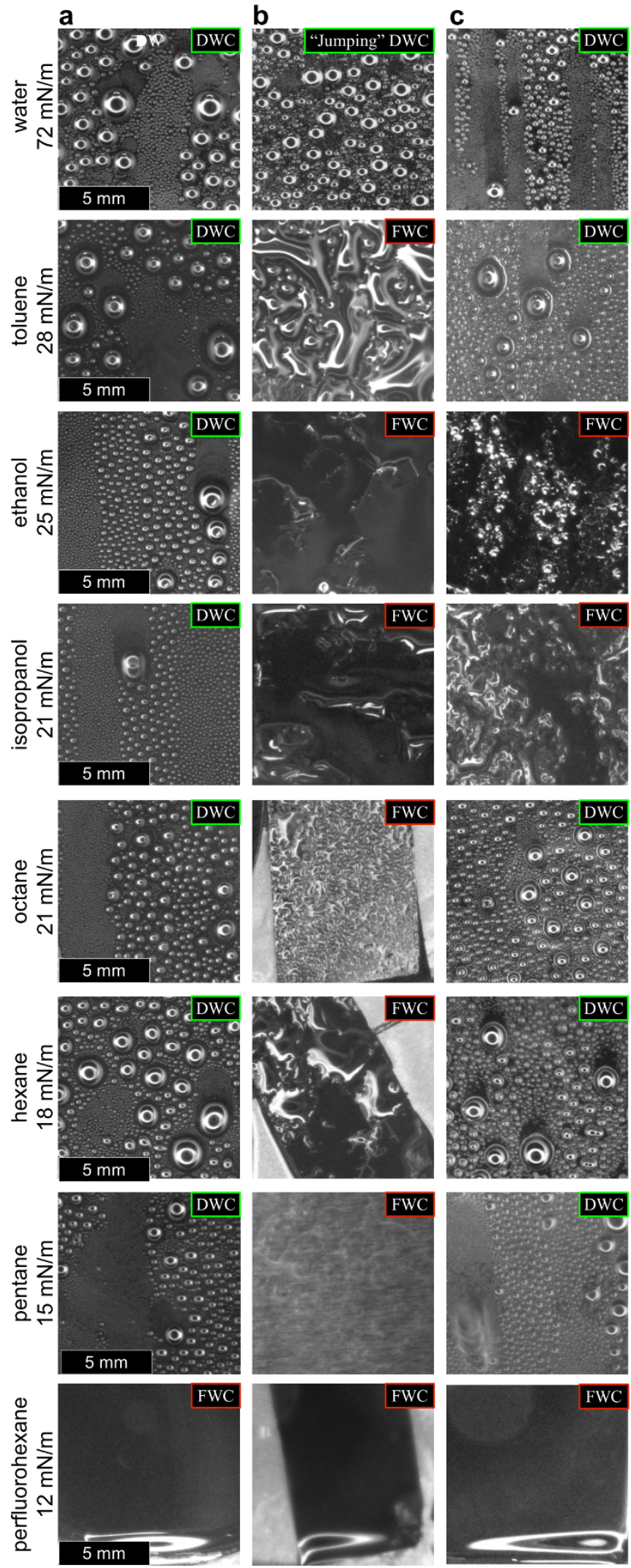

Figure 3 Effect of condensate interfacial tension on condensation mode on different surfaces. Condensation of various low-surface tension fluids on a (a) flat oleophobic surface, (b) unimpregnated nanotexture, and (c) Krytox-impregnated nanotexture. DWC and FWC stand for dropwise and filmwise condensation, respectively.

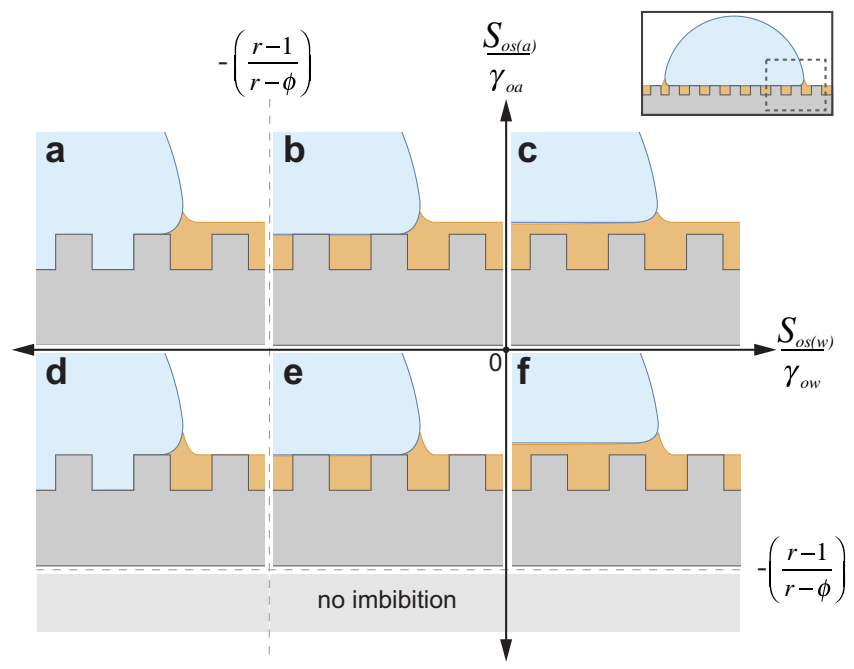

Figure $4 \mid$ Wetting states of condensing fluids on Krytox-impregnated surfaces. The $x$-axis shows the spreading ratio of the lubricant on the solid in the presence of condensate. Dotted vertical lines correspond to roughness ratios on nanotexture and superomniphobic texture.

since it is miscible with Krytox, are calculated from Eq. 2 and depicted in Fig. 4a, b, c. It has been shown that if the spreading coefficient $\left(S_{\mathrm{ls}(\mathrm{c})}\right)$ of the lubricant (subscript 1 ) on the solid (subscript $s$ ) in the presence of condensate (subscript $c$ ) is greater than zero, i.e. $S_{l s(c)}>0$, then the condensate drops will float on a thin film of lubricant with virtually no pinning (Fig. $4 \mathrm{c})^{64}$. If $S_{l s(c)}<0$, then in order to prevent the condensate from displacing the lubricant (Fig. 4a), the surface lubricant and solid must possess surface energies in relation to the surface roughness such that

$$
-\left(\frac{r-1}{r-\phi}\right)<\frac{S_{l(c)}}{\gamma_{l c}}<0
$$

where $r$ is the ratio of the actual surface area to the projected surface area and $\phi$ is the solid/condensate fraction ${ }^{64}$. We observed that isopropanol and ethanol exhibited filmwise condensation. These liquids have a higher liquid/vapor interfacial tension than pentane and hexane, thus it was surprising to see that they display filmwise behavior while pentane and hexane displayed robust dropwise shedding behavior. This behavior can be explained by noting that the spreading coefficient of Krytox in the presence of isopropanol and ethanol is much lower than with pentane or hexane (Fig. 4d), so the former two liquids act to destabilize the lubricant film and impale the solid texture. These experiments highlight the importance of the spreading coefficients of the lubricant on the solid surface not only in the presence of vapor, shown below in Table 2, but also in the presence of the condensate.

The average base diameters of shedding drops were measured (see Table 3) to further investigate the effects of wetting state on condensation behavior. We observe a difference in shedding diameter of the different liquids on the same surface, which do not follow the same trend as the departure diameters on the smooth oleophobic surface. We attribute this behavior to the difference in wetting state of the lubricant film beneath the condensate drops. The small departing diameters of toluene $(1.3 \pm 0.2 \mathrm{~mm})$ and pentane $(1.2 \pm 0.1 \mathrm{~mm})$ compared to hexane $(2.4 \pm 0.1 \mathrm{~mm})$ and octane $(2.2 \pm 0.2 \mathrm{~mm}) \mathrm{can}$ be explained by their larger spreading ratio. Since the spreading coefficient of Krytox in the presence of toluene and pentane is larger than with hexane and octane, the former two liquids tend to stabilize the lubricant film underneath condensate drops, leading to reduced pinning and thus smaller departing diameters.

To further elucidate the influence of texture on the stability of the lubricant film, we investigated the condensation of pentane on the 
Table 2 | Condensate/lubricant interfacial tensions and spreading coefficients

\begin{tabular}{lcccc} 
& $\begin{array}{c}\sigma_{c v} \\
{[\mathrm{mN} / \mathrm{m}]}\end{array}$ & $\begin{array}{c}\sigma_{l c} \\
{[\mathrm{mN} / \mathrm{m}]}\end{array}$ & $\begin{array}{c}S_{l c(v)} \\
{[\mathrm{mN} / \mathrm{m}]}\end{array}$ & $\begin{array}{c}S_{c l(v)} \\
{[\mathrm{mN} / \mathrm{m}]}\end{array}$ \\
\hline water & 72 & 49 & 6 & -104 \\
toluene & 28 & 8 & -38 & -19 \\
ethanol & 23 & 8 & -32 & -15 \\
isopropanol & 22 & 7 & -32 & -11 \\
pentane & 16 & 3 & -30 & -1 \\
hexane & 18 & 4 & -32 & -5 \\
octane & 22 & 5 & -34 & -10 \\
\hline
\end{tabular}

impregnated superomniphobic and micropost textures (Fig. 5b, c). We observed that the behavior of pentane condensation on these surfaces was strongly influenced by the underlying solid texture. As with condensation on the impregnated nanotexture, the impregnated superomniphobic texture exhibited sustained shedding of drops (Fig. 5b). We also observed that the pinning of shedding droplets increased over time on the impregnated superomniphobic texture. The drops shown in Figs. $5 \mathrm{a}$ and $\mathrm{b}$ illustrate that this effect was much more pronounced on the superomniphobic texture (see also Supplemental Videos 2 and 3).

The increased pinning to the impregnated superomniphobic texture can be explained by the larger exposed area fraction of the roughness features. The SEM images in Fig. 2d and e show topology of the impregnated nanotexture and superomniphobic texture after about 10 minutes of pentane condensation. The high area fraction of microscale topological features protruding above the lubricant level on the impregnated re-entrant texture explains the higher degree of drop pinning observed on this surface as compared to the relatively smooth impregnated nanotexture ${ }^{17,64}$.

On the impregnated microposts, the behavior was starkly different from the other two impregnated textures. Only a small number drops formed and either remained stationary or shed and aggregated at the bottom of the sample (Fig. 5c). Supplemental Video 4 also shows that contact between drops did not necessarily lead to their coalescence, and that in some cases secondary drops on top of primary drops were present ${ }^{17}$. After $30 \mathrm{sec}$, further cooling of the surface did not result in formation of any additional drops. We observed that after evaporation of pentane, triggered by raising the cooling plate temperature, the sample had exhibited significant morphological heterogeneities not present prior to condensation.

We attribute the unusual behavior on the impregnated microposts to the displacement of the lubricant by the condensate as predicted by Eq. 2. Since the roughness of the micropillars is much lower than that of either the impregnated nanotexture or superomniphobic texture, the critical spreading ratio that leads to impalement is not as low for this surface. As indicated by Fig. 5, all liquids except water have a spreading ratio that is sufficiently low to cause impalement of the microposts by the condensate. This hypothesis is further supported by observation of the morphology of the surface after pentane evaporation. Fig. $5 \mathrm{c}$ and $\mathrm{S} 3$ shows that the heterogeneities after condensation correspond to regions in which oil was displaced from the surface. Additionally, the image sequences in Fig. S3c shows that Krytox, which accumulated at the bottom of the sample after dewetting, slowly wicks back in-between the micro-pillars leading to selfhealing of the lubricant-impregnated surface.

\section{Discussion}

Enhancement of heat transfer coefficients of low-surface tension fluids. To determine the enhancement of dropwise over filmwise condensation modes, we measured the heat transfer coefficients for ethanol, pentane, and hexane on flat hydrophilic and flat oleophobic surfaces. The corresponding values for dropwise condensation were
Table 3 | Base diameters of condensing drops shedding from flat oleophobic surface and Krytox-impregnated nanotexture measured at 10-minute intervals

\begin{tabular}{|lcccc} 
& $\begin{array}{c}\text { smooth } \\
\text { oleophobic } \\
\text { surface }\end{array}$ & \multicolumn{3}{c}{$\begin{array}{c}\text { Krytox-impregnated } \\
\text { nanotexture }\end{array}$} \\
\cline { 2 - 5 } liquid & $d_{\text {base }}$ & $d_{\text {base }}(0 \mathrm{~min})$ & $d_{\text {base }}(10 \mathrm{~min})$ & $d_{\text {base }}(20 \mathrm{~min})$ \\
\hline water & $2.2 \pm 0.2$ & $1.0 \pm 0.1$ & $1.0 \pm 0.1$ & $1.0 \pm 0.1$ \\
toluene & $2.7 \pm 0.6$ & $0.8 \pm 0.1$ & $1.3 \pm 0.2$ & $1.5 \pm 0.1$ \\
ethanol & $2.0 \pm 0.1$ & filmwise & filmwise & filmwise \\
isopropanol & $1.9 \pm 0.2$ & filmwise & filmwise & filmwise \\
pentane & $1.5 \pm 0.1$ & $0.8 \pm 0.1$ & $1.2 \pm 0.1$ & $1.5 \pm 0.2$ \\
hexane & $2.5 \pm 0.1$ & $2.3 \pm 0.2$ & $2.4 \pm 0.1^{\mathrm{a}}$ & $2.8 \pm 0.2^{\mathrm{a}}$ \\
octane & $1.8 \pm 0.3$ & $2.1 \pm 0.2$ & $2.2 \pm 0.2$ & $2.3 \pm 0.2$ \\
\hline ameasured at 7.5 min and $15 \mathrm{~min}$. & & & \\
\hline
\end{tabular}

also estimated theoretically by substituting the experimentally measured droplet departure diameters and average contact angles into Kim and Kim's model. For filmwise condensation an equivalent heat transfer coefficient was estimated using a linear fit to the Nusselt model over $\Delta T$ range of $0 \mathrm{~K}$ to $10 \mathrm{~K}$. The plot in Fig. 6 shows close agreement between the measured and calculated values. This plot also demonstrates a four to eight-fold enhancement in heat transfer coefficient for dropwise vs. filmwise condensation for the three fluids. We also used the two models to predict the heat transfer coefficient enhancement for the remaining fluids on both smooth oleophobic surfaces and Krytox-impregnated nanotexture. The plot in Figure 6 shows that for all fluids the predicted heat transfer coefficient enhancement on smooth oleophobic surfaces was in the four to eight-fold range, but was smaller, in the two to six-fold range, for the Krytox-impregnated nanotexture. The difference in the enhancement value on these two types surfaces stems from the thermal resistance introduced by the lubricant layer.

In summary, we studied the condensation modes of fluids with surface tension in the range of $12-30 \mathrm{mN} / \mathrm{m}$ on oleophobic, superomniphobic, and lubricant-impregnated surfaces. We demonstrated that smooth oleophobic and stable lubricant-impregnated surfaces promote continual droplet formation and shedding of a majority of the studied fluids, whereas the studied unimpregnated superomniphobic textures become flooded due to nucleation within their re-entrant texture. By promoting dropwise condensation, we demonstrate a four to eight-fold increase in heat transfer coefficient as compared to filmwise condensation. This enhancement in heat transfer coefficient demonstrated for pentane can significantly improve efficiency of organic Rankine cycles used for heat recovery from low temperature sources such as biomass combustion, industrial waste, or geothermal heat sources. Further increases in heat transfer coefficients on lubricant-impregnated surfaces could be realized by using higher thermal conductivity lubricant, minimizing the solid pinned fraction or using a lubricant-solid pair that have positive spreading coefficient in the presence of the condensate, which may also reduce lubricant drainage. Although the results for most of the studied fluids are promising, this study demonstrates the significant difficulty in promoting dropwise condensation of ultra-low-surface tension liquids, specifically fluorocarbon liquids. Future work should be directed toward the development of durable ultra-low-surface energy modifiers, and also to lubricants that are not non-wetting to fluorinated refrigerants.

\section{Methods}

Surface fabrication and characterization. The nanostructured superhydrophobic alumina-silica surfaces were fabricated using RPX-540 manufactured by Integrated 

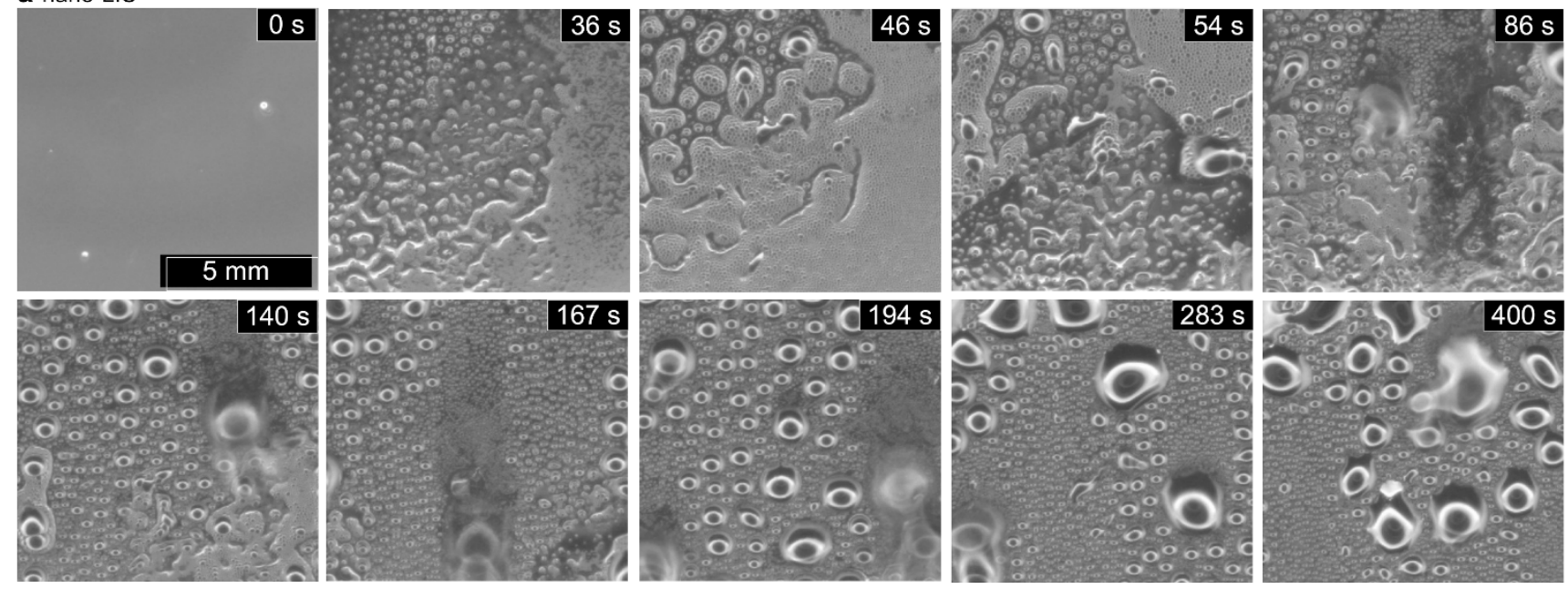

b micro/nano-LIS
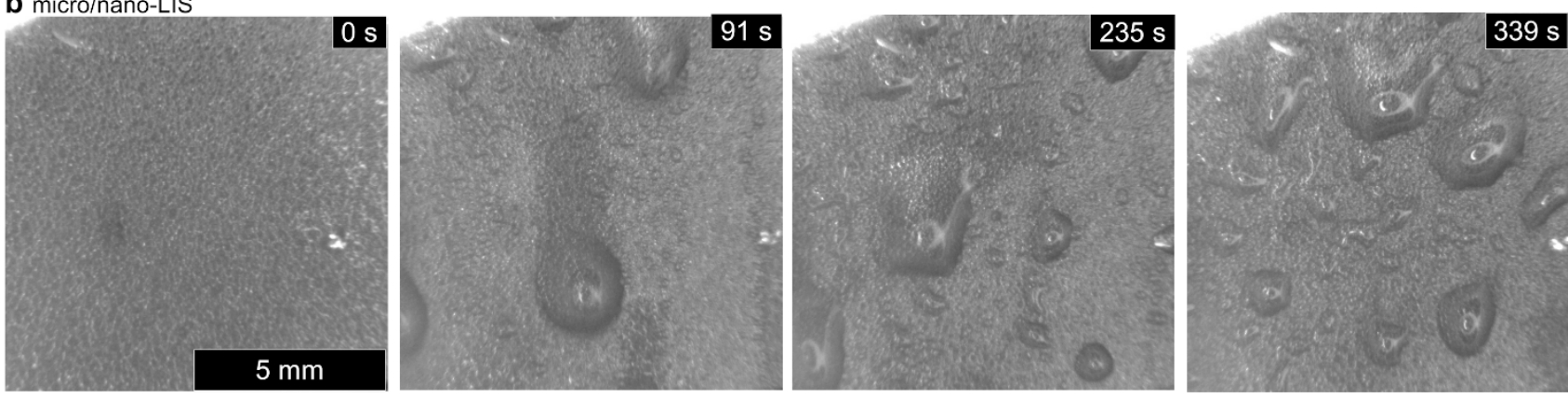

C micro-LIS
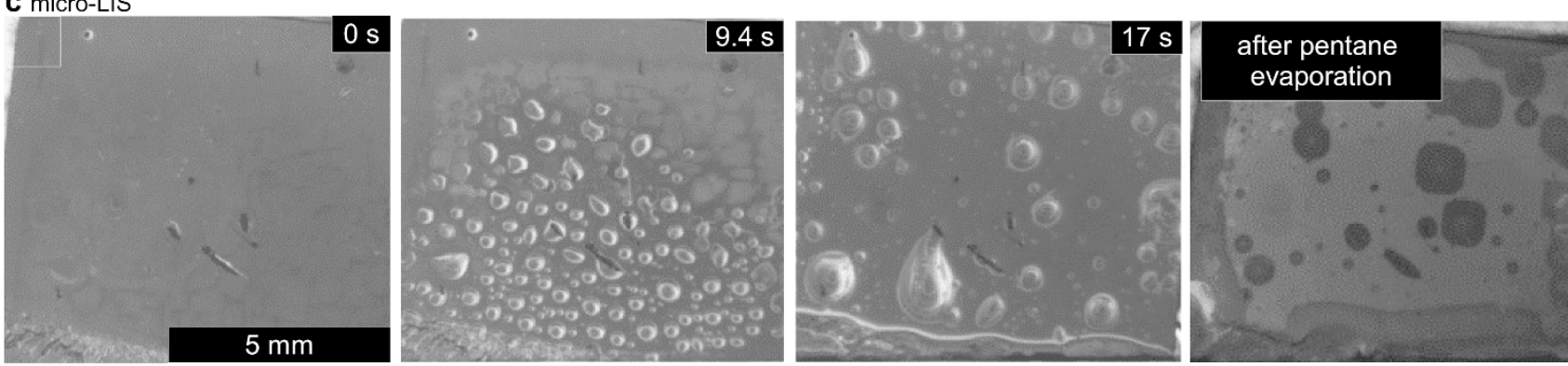

Figure $5 \mid$ Effect of texture of lubricant-impregnated surfaces on condensation. (a) Condensation on Krytox-impregnated nanotexture with excess lubricant, clearing off by $\sim 140 \mathrm{sec}$. (b) Krytox-impregnated superomniphobic texture with highly-pinned drops. (c) Impregnated microposts are displaced by condensing pentane.

Surface Technologies ${ }^{67}$. Briefly, silicon wafers were coated by nanoparticles synthesized via vapor phase reaction of trimethylaluminium and water, which were then encapsulated in a silicon oxide matrix via atomic layer deposition. The resulting nanotexture was functionalized via vapor phase deposition of tridecafluoro-1,1,2,2tetrahydrooctyltrichlorosilane. Flat silicon wafers functionalized using this coating exhibited an advancing water contact angle of $111^{\circ} \pm 4^{\circ}$

The re-entrant superomniphobic surfaces were prepared by spray coating a polymer solution using an airbrush under a pressurized nitrogen stream. Commercially available poly(methyl methacrylate) (Sigma, $\mathrm{Mw} \sim 102 \mathrm{kDa}$ ) was mixed with the low surface energy molecule fluorodecyl polyhedral oligomeric sesquisiloxane in a 50/50 weight percentage ratio. The common solvent used to prepare a solution was the commercially available HCFC solvent, Asahiklin AK-225 (Asahi Glass Company). The concentration of the solution was $50 \mathrm{mg} / \mathrm{ml}$. The solution was mechanically stirred for 8 hours to prepare a clear transparent solution. The solution was then sprayed at a pressure of $170 \mathrm{kPa}$ at an operating distance of $20 \mathrm{~cm}$ onto a flat silicon wafer, which deposits liquid-repellent corpuscular microbeads of poly(methyl methacrylate ${ }^{68}$.

The silicon microposts were fabricated using standard photolithography to form a pattern of posts with a width of $10 \mu \mathrm{m}$ and spacing of $5 \mu \mathrm{m}$, and were then etched to a depth of $10 \mu \mathrm{m}$ via deep reactive ion etching. The etched microposts were cleaned using Piranha solution $\left(\mathrm{H}_{2} \mathrm{SO}_{4}: \mathrm{H}_{2} \mathrm{O}_{2} 4: 1\right)$ and were functionalized with octadecyltrichlorosilane (Sigma-Aldrich) using a solution-based deposition method. Smooth silicon wafers functionalized using this method exhibited an advancing water contact angle of $110 \pm 4^{\circ}$.
Lubricant impregnation of the textured surfaces was achieved by dipping them in bath of the Krytox oil. The excess of the oil was removed through gravity draining and blowing with nitrogen gas.

Contact angle measurement. To minimize effects of test liquid evaporation, contact angles were measured by a goniometer (ramé-hart Model 590 Advanced) in air saturated with the vapor of the test liquid. Sample surfaces were supported above a small pool of the test liquid inside a quartz test cell whose top was sealed by Parafilm, and the test cell was allowed to equilibrate for 10 minutes. After drawing the test liquid into a 30-gauge needle, the needle was lowered to puncture through the Parafilm and access the sample. A $1 \mu \mathrm{L}$ drop was dispensed from the needle to wet the surface, and the volume was increased from $1 \mu \mathrm{L}$ to $5 \mu \mathrm{L}$. The advancing contact angle was measured while the contact line advanced across the surface. Similarly, the receding contact angle was measured as liquid was withdrawn from the drop and the contact line receded across the surface. Measurements were repeated at four different locations on each surface. All reported diameter values are averages of four measurements with associated standard errors reported with a coverage factor of one.

Condensation experiments. Visualization of the condensation behavior of different fluids was performed inside a condensation chamber (Fig. S2). After mounting of the sample using double-sided copper tape on the aluminum back-plate, the bottom of the chamber was filled with $25 \mathrm{~mL}$ to $100 \mathrm{~mL}$ of the liquid. Perfluorohexane $(99 \%$, Sigma-Aldrich), pentane (99\%, Sigma-Aldrich), $n$-hexane (95\%, J. T. Baker), isopropanol (99.99\%, Fisher), ethanol (99.5\%, Sigma-Aldrich), $n$-octane (99\%, 


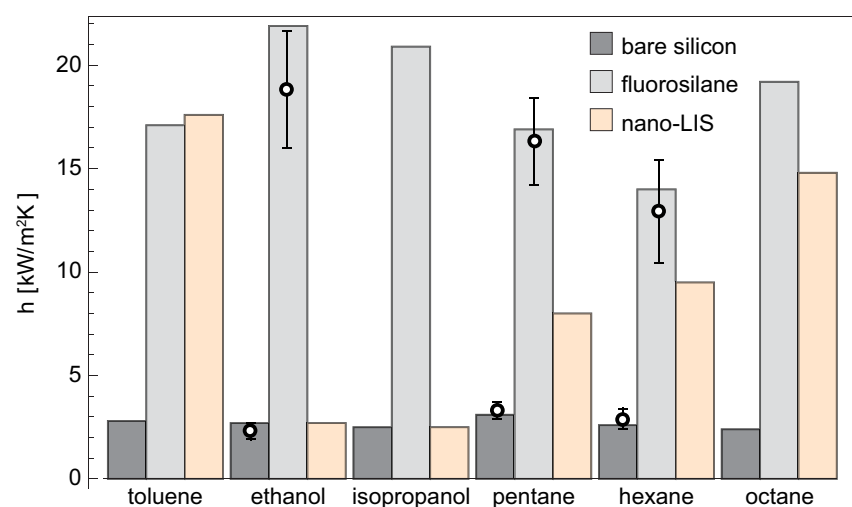

Figure 6 Measured and predicted enhancement of heat transfer coefficients. The predicted filmwise HTC (bare silicon surface) was calculated from linear fit to Nusselt model and the predicted dropwise HTC on smooth oleophobic surface (flourosilane) and Krytoximpregnated nanotexture (nano-LIS) was calculated using Eq. S2 with experimentally-determined departing diameters from Table 3. Experimental measurements are indicated with points.

anhydrous, Sigma-Aldrich), toluene, (99.8\%, Sigma-Aldrich) and deionized water were used as working fluids. The pressure within the chamber was reduced using house vacuum down to about $50 \mathrm{kPa}$. After pumping down for about $30 \mathrm{~s}$ to $60 \mathrm{~s}$, the vacuum valve was closed and temperature of the sample was reduced using a watercooled Peltier element mounted to the outer side of the back-plate. Temperatures were monitored using a K-type thermocouple placed in a recess drilled into the backplate. To minimize the thermal contact resistance, silicon thermal grease (DowCorning) was applied between the Peltier element and the aluminum back-plate. The sample was illuminated using a ring light (Nikon) and imaged using a CMOS camera (ImagingSource) with a $10 \times$ objective lens. Images of the condensation process were captured for a period of 30 to 90 minutes with frequency of $5 \mathrm{~Hz}$ to $0.2 \mathrm{~Hz}$, dependent on the rate of condensation of particular fluid. The images were manually analyzed using FIJI image analysis software. All reported diameter values are averages of six measurements with associated standard errors reported with a coverage factor of one. To ensure that residual water vapor in the chamber did not affect the condensation process, a control experiment was carried out by evacuating the chamber without a liquid and reducing the temperature of the back-plate to $-5^{\circ} \mathrm{C}$. No condensation or frost formation was observed on the back-plate and mounted silicon wafer after 30 minutes of cooling, indicating a negligible amount of residual moisture in the chamber.

Heat transfer coefficient measurements. Heat transfer coefficients were measured by introducing vapor to a chilled sample surface with diameter $50 \mathrm{~mm}$ held in an evacuated chamber. The back side of the sample was chilled by forced cooled water. A vial of condensate liquid was immersed in a circulating water bath held at $35-40^{\circ} \mathrm{C}$ depending on the vapor pressure of the condensate. A vacuum vent was held near the point of heat transfer measurement to exhaust any non-condensable gases that may have accumulated in the chamber. Exhaust rates were less than $1 \mathrm{sccm}$ and did not noticeably perturb condensation behavior. Sample temperatures were measured by $2252 \mathrm{kOhm}$ thermistors (T337, Redfish Sensors) embedded $25 \mathrm{~mm}$ into a metal block behind the sample surface at precisely known locations. The thermistors were calibrated to $\pm 0.01{ }^{\circ} \mathrm{C}$ using a platinum resistance probe (T100, Isotech) immersed in a circulating bath (FP-25, Julabo) filled with 50/50 water/ethylene glycol held to \pm $0.01^{\circ} \mathrm{C}$. The measurements of $\mathrm{dT} / \mathrm{dx}$, along with the thermal conductivity of the block, were used to determine the surface temperature. Saturated vapor temperature was determined from an Arrhenius correlation fitted to the range of $5-20^{\circ} \mathrm{C}$, with residuals less than $0.01^{\circ} \mathrm{C}$. Saturation pressure was measured by a high-accuracy pressure transducer (PX01 Omega) calibrated to $\pm 0.15 \%$ reading against a precision manometer (629B, MKS Instruments). Subcooling temperatures were thereby measured to accuracies better than $0.08^{\circ} \mathrm{C}$. Measurements were taken after the apparatus had been allowed to reach steady state for $30 \mathrm{~min}$.

Certain commercial equipment, instruments, and materials are identified in this publication to adequately specify the experimental procedure. Such identification in no way implies approval, recommendation, or endorsement by NIST, nor does it imply that the equipment, instruments, or materials identified are necessarily the best available for the purpose.

1. Hung, T. C., Shai, T. Y. \& Wang, S. K. A review of organic rankine cycles (ORCs) for the recovery of low-grade waste heat. Energy 22, 661-667 (1997).

2. Luijten, C. C. M., van Hooy, R. G. P., Janssen, J. W. F. \& van Dongen, M. E. H. Multicomponent nucleation and droplet growth in natural gas. J. Chem. Phys. 109, 3553-3558 (1998).
3. Castle, W. F. Air separation and liquefaction: recent developments and prospects for the beginning of the new millennium. Int. J. Refrig. 25, 158-172 (2002).

4. Kandlikar, S. G., Garimella, S., Li, D., Colin, S. \& King, M. R. Heat Transfer and Fluid flow in Minichannels and Microchannels. (Elsevier, 2006).

5. Rufford, T. E. et al. The removal of $\mathrm{CO} 2$ and $\mathrm{N} 2$ from natural gas: A review of conventional and emerging process technologies. J. Pet. Sci. Eng. 94-95, 123-154 (2012).

6. Tanasawa, I. Advances in Heat Transfer. (Academic Press, 1991).

7. Schmidt, E., Schurig, W. \& Sellschopp, W. Versuche über die Kondensation von Wasserdampf in Film- und Tropfenform. Tech. Mech. Thermodyn. 1, 53-63 (1930).

8. Mikic, B. B. On mechanism of dropwise condensation. Int. J. Heat Mass Transf. 12, 1311-1323 (1969).

9. Welch, J. F. \& Westwater, J. W. Microscopic study of dropwise condensation. (Doctoral dissertation, University of Illinois at Urbana-Champaign, 1961).

10. Tanaka, H. \& Tsuruta, T. A microscopic study of dropwise condensation. Int. J. Heat Mass Transf. 27, 327-335 (1984).

11. Rose, J. W. Dropwise condensation theory and experiment: A review. Proc. Inst. Mech. Eng. Part J. Power Energy 216, 115-128 (2002).

12. Rausch, M. H., Leipertz, A. \& Fröba, A. P. Dropwise condensation of steam on ion implanted titanium surfaces. Int. J. Heat Mass Transf. 53, 423-430 (2010).

13. Boreyko, J. \& Chen, C. Self-Propelled Dropwise Condensate on Superhydrophobic Surfaces. Phys. Rev. Lett. 103, 184501 (2009).

14. Varanasi, K. K., Hsu, M., Bhate, N., Yang, W. \& Deng, T. Spatial control in the heterogeneous nucleation of water. Appl. Phys. Lett. 95, 094101 (2009).

15. Dietz, C., Rykaczewski, K., Fedorov, A. G. \& Joshi, Y. Visualization of droplet departure on a superhydrophobic surface and implications to heat transfer enhancement during dropwise condensation. Appl. Phys. Lett. 97, 033104 (2010).

16. Miljkovic, N., Enright, R. \& Wang, E. N. Effect of Droplet Morphology on Growth Dynamics and Heat Transfer during Condensation on Superhydrophobic Nanostructured Surfaces. ACS Nano 6, 1776-1785 (2012).

17. Anand, S., Paxson, A. T., Dhiman, R., Smith, J. D. \& Varanasi, K. K. Enhanced Condensation on Lubricant-Impregnated Nanotextured Surfaces. ACS Nano 6, 10122-10129 (2012).

18. Azimi, G., Dhiman, R., Kwon, H.-M., Paxson, A. T. \& Varanasi, K. K. Hydrophobicity of rare-earth oxide ceramics. Nat. Mater. 12, 315-320 (2013).

19. Paxson, A. T., Yagüe, J. L., Gleason, K. K. \& Varanasi, K. K. Stable Dropwise Condensation for Enhancing Heat Transfer via the Initiated Chemical Vapor Deposition (iCVD) of Grafted Polymer Films. Adv. Mater. 26, 418-423 (2013).

20. Anderson, D. M. et al. Using Amphiphilic Nanostructures To Enable Long-Range Ensemble Coalescence and Surface Rejuvenation in Dropwise Condensation. ACS Nano 6, 3262-3268 (2012).

21. Torresin, D., Tiwari, M. K., Del Col, D. \& Poulikakos, D. Flow Condensation on Copper-Based Nanotextured Superhydrophobic Surfaces. Langmuir 29, 840-848 (2013).

22. Lu, Z. Film condensation of the component part of natural gas and heat transfer enhanced by surface longitudinal groove. (Master's thesis, Shanghai Jiao Tong University, 1996).

23. Rose, J. W. Surface Tension Effects and Enhancement of Condensation Heat Transfer. Chem. Eng. Res. Des. 82, 419-429 (2004).

24. Ghiaasiaan, S. M. Two-Phase Flow, Boiling, and Condensation: In Conventional and Miniature Systems. (Cambridge University Press, 2008).

25. Carey, V. P. Liquid-Vapor Phase-Change Phenomena. (Hemisphere Publishing, 2008).

26. Webb, R. L. \& Kim, N.-H. Principles of Enhanced Heat Transfer. (Taylor \& Francis, 2005).

27. Topper, L. \& Baer, E. Dropwise condensation of vapors and heat transfer rates. J. Colloid Sci. 10, 225-226 (1955).

28. Mizushina, T., Kamimura, H. \& Kuriwaki, Y. Tetrafluoroethylene coatings on condenser tubes. Int. J. Heat Mass Transf. 10, 1015-1016 (1967).

29. Wilmhurst, R. Heat transfer during dropwise condensation of steam, ethane 1, 2 diol, aniline and nitrobenzene. (Doctoral Dissertattion, Queen Mary University of London, 1979).

30. Wang, Y.-X. \& Plawsky, J. L. P. C. W. J. Optical Measurement of Microscale Transport Processes in Dropwise Condensation. Microscale Thermophys. Eng. 5, 55-69 (2001).

31. Gokhale, S. J., Plawsky, J. L. \& Wayner Jr, P. C. Effect of interfacial phenomena on dewetting in dropwise condensation. Adv. Colloid Interface Sci. 104, 175-190 (2003).

32. Mirkovich, V. V. \& Missen, R. W. Non-filmwise condensation of binary vapors of miscible liquids. Can. J. Chem. Eng. 39, 86-87 (1961).

33. Mirkovich, V. V. \& Missen, R. W. A study of the condensation of binary vapors of miscible liquids: Part 2: Heat transfer co-efficients for filmwise and non-filmwise condensation. Can. J. Chem. Eng. 41, 73-78 (1963).

34. Utaka, Y. \& Wang, S. Characteristic curves and the promotion effect of ethanol addition on steam condensation heat transfer. Int. J. Heat Mass Transf. 47, 4507-4516 (2004).

35. Murase, T., Wang, H. S. \& Rose, J. W. Marangoni condensation of steam-ethanol mixtures on a horizontal tube. Int. J. Heat Mass Transf. 50, 3774-3779 (2007).

36. Maråk, K. A. Condensation Heat Transfer and Pressure Drop for Methane and Binary Methane Fluids in Small Channels. (Doctoral Dissertation, Kristianstad University, 2009). 
37. Li, Y., Wang, G., Yan, J. \& Wang, J. A Semi-Empirical Model for Condensation Heat Transfer Coefficient of Mixed Ethanol-Water Vapors. J. Heat Transf. 133, 061501 (2011).

38. Ali, H., Wang, H. S., Briggs, A. \& Rose, J. W. Effects of Vapor Velocity and Pressure on Marangoni Condensation of Steam-Ethanol Mixtures on a Horizontal Tube. J. Heat Transf. 135, 031502 (2013).

39. Davies, G. A., Mojtehedi, W. \& Ponter, A. B. Measurement of contact angles under condensation conditions. The prediction of dropwise-filmwise transition. Int. J. Heat Mass Transf. 14, 709-713 (1971).

40. Rykaczewski, K. Microdroplet Growth Mechanism during Water Condensation on Superhydrophobic Surfaces. Langmuir 28, 7720-7729 (2012).

41. Lee, S. et al. Heat transfer measurement during dropwise condensation using micro/nano-scale porous surface. Int. J. Heat Mass Transf. 65, 619-626 (2013).

42. Kim, S. \& Kim, K. J. Dropwise condensation modeling suitable for superhydrophobic surfaces. J. Heat Transf. 133, 081502 (2011).

43. Zhao, H. \& Beysens, D. From droplet growth to film growth on a heterogeneous surface: condensation associated with a wettability gradient. Langmuir 11, 627-634 (1995).

44. Boreyko, J. B., Zhao, Y. \& Chen, C.-H. Planar jumping-drop thermal diodes. Appl. Phys. Lett. 99, 234105 (2011).

45. Miljkovic, N. et al. Jumping-Droplet-Enhanced Condensation on Scalable Superhydrophobic Nanostructured Surfaces. Nano Lett. 13, 179-187 (2012).

46. Rykaczewski, K. et al. How nanorough is rough enough to make a surface superhydrophobic during water condensation? Soft Matter 8, 8786 (2012).

47. Rykaczewski, K. et al. Multimode Multidrop Serial Coalescence Effects during Condensation on Hierarchical Superhydrophobic Surfaces. Langmuir 29, 881-891 (2013).

48. Lafuma, A. \& Quéré, D. Superhydrophobic states. Nat. Mater. 2, 457-460 (2003).

49. Nosonovsky, M. \& Bhushan, B. Biomimetic Superhydrophobic Surfaces: Multiscale Approach. Nano Lett. 7, 2633-2637 (2007).

50. Dorrer, C. \& Rühe, J. Some thoughts on superhydrophobic wetting. Soft Matter 5 51 (2009).

51. Tuteja, A., Choi, W., Mabry, J. M., McKinley, G. H. \& Cohen, R. E. Robust Omniphobic Surfaces. Proc. Natl. Acad. Sci. 105, 18200-18205 (2008).

52. Tuteja, A. et al. Designing Superoleophobic Surfaces. Science 318, 1618-1622 (2007).

53. Deng, X., Mammen, L., Butt, H.-J. \& Vollmer, D. Candle Soot as a Template for a Transparent Robust Superamphiphobic Coating. Science 335, 67-70 (2012).

54. Wier, K. \& McCarthy, T. Condensation on ultrahydrophobic surfaces and its effect on droplet mobility: Ultrahydrophobic surfaces are not always water repellant. Langmuir 22, 2433-2436 (2006).

55. Narhe, R. D. \& Beysens, D. A. Water condensation on a super-hydrophobic spike surface. Europhys. Lett. EPL 75, 98-104 (2006).

56. Dorrer, C. \& Rühe, J. Condensation and wetting transitions on microstructured ultrahydrophobic surfaces. Langmuir 23, 3820-3824 (2007).

57. Jung, Y. C. \& Bhushan, B. Wetting behaviour during evaporation and condensation of water microdroplets on superhydrophobic patterned surfaces. J. Microsc. 229, 127-140 (2008)

58. Varanasi, K. K., Deng, T., Smith, J. D., Hsu, M. \& Bhate, N. Frost formation and ice adhesion on superhydrophobic surfaces. Appl. Phys. Lett. 97, 234102 (2010).

59. Verheijen, H. J. J. \& Prins, M. W. J. Reversible Electrowetting and Trapping of Charge: Model and Experiments. Langmuir 15, 6616-6620 (1999).
60. Krupenkin, T. N. et al. Reversible Wetting-Dewetting Transitions on Electrically Tunable Superhydrophobic Nanostructured Surfaces. Langmuir 23, 9128-9133 (2007).

61. Quéré, D. Non-sticking drops. Rep. Prog. Phys. 68, 2495-2532 (2005).

62. Wong, T.-S. et al. Bioinspired self-repairing slippery surfaces with pressure-stable omniphobicity. Nature 477, 443-447 (2011).

63. Lafuma, A. \& Quéré, D. Slippery pre-suffused surfaces. EPL Europhys. Lett. 96, 56001 (2011).

64. Smith, J. D. et al. Droplet mobility on lubricant-impregnated surfaces. Soft Matter 9, 1772 (2013).

65. Kim, P., Kreder, M. J., Alvarenga, J. \& Aizenberg, J. Hierarchical or Not? Effect of the Length Scale and Hierarchy of the Surface Roughness on Omniphobicity of Lubricant-Infused Substrates. Nano Lett. 13, 1793-1799 (2013).

66. Daniel, D., Mankin, M. N., Belisle, R. A., Wong, T.-S. \& Aizenberg, J. Lubricantinfused micro/nano-structured surfaces with tunable dynamic omniphobicity at high temperatures. Appl. Phys. Lett. 102, 231603 (2013).

67. Chinn, J. et al. Durable Super-Hydrophobic Nano-Composite Films. NSTINanotech 2010 1, (2010).

68. Srinivasan, S., Chhatre, S. S., Mabry, J. M., Cohen, R. E. \& McKinley, G. H. Solution spraying of poly(methyl methacrylate) blends to fabricate microtextured, superoleophobic surfaces. Polymer 52, 3209-3218 (2011).

69. Wenzel, R. Resistance of solid surfaces to wetting by water. Ind. Eng. Chem. 28, (1936)

70. Quéré, D. Wetting and Roughness. Annu. Rev. Mater. Res. 38, 71-99 (2008)

\section{Acknowledgments}

K.R. gratefully acknowledges support from Ira A. Fulton Schools of Engineering at Arizona State University. A.T.P. gratefully acknowledges funding support from the NSF GRFP. K.K.V. gratefully acknowledges support from NSF Career award no. 0952564 and MIT Energy Initiative.

\section{Author contributions}

K.R., A.T.P., S.A., K.K.V. and J.H.J.S. envisioned and planned the experiments. K.R., A.T.P., M.L.W., M.S. and S.A. performed the experiments. A.T.P. and M.S. fabricated the condensation rig. S.S., G.H.M., J.C. and M.L.W. fabricated the samples. K.R. did hea transfer modeling and A.T.P. measured the heat transfer coefficients. X.S. performed the image analysis. All authors contributed to writing and approved the manuscript. M.S. and M.L.W. contributed equally as joint second author.

\section{Additional information}

Supplementary information accompanies this paper at http://www.nature.com/ scientificreports

Competing financial interests: The authors declare no competing financial interests.

How to cite this article: Rykaczewski, K. et al. Dropwise Condensation of Low Surface Tension Fluids on Omniphobic Surfaces. Sci. Rep. 4, 4158; DOI:10.1038/srep04158 (2014).

This work is licensed under a Creative Commons Attribution-

NonCommercial-NoDerivs 3.0 Unported license. To view a copy of this license, visit http://creativecommons.org/licenses/by-nc-nd/3.0 